\title{
LOCAL RECRUITMENT IN THE GREATER FLAMINGO: A NEW APPROACH USING CAPTURE-MARK-RECAPTURE DATA
}

\author{
Roger Pradel, ${ }^{1,2}$ Alan R. Johnson,,${ }^{1}$ Anne Viallefont, ${ }^{2}$ Ruedi G. Nager, ${ }^{1}$ And Frank CézILly ${ }^{1,3,4}$ \\ ${ }^{1}$ Station Biologique de la Tour du Valat, Le Sambuc, 13200 Arles, France \\ ${ }^{2}$ Centre d'Ecologie Fonctionnelle et Evolutive, Centre National de la Recherche Scientifique, Montpellier, France \\ ${ }^{3}$ Laboratoire d'Ecologie, Université de Bourgogne, 21011 Dijon Cédex, France
}

\begin{abstract}
Although the establishment of new individuals in the breeding component of a population is an essential feature of population regulation, only a few attempts have been made to test biological hypotheses about recruitment. Most previous studies rely on ad hoc calculations or are flawed with unwarranted assumptions about survival. We use a recently developed approach, based on capture-mark-recapture, in which analysis of local recruitment is similar to a time-reversed analysis of survival. The basic data set consists of capture histories viewed in reverse order, with initial capture at year of birth, and subsequent observations corresponding to years when the animal has bred. The model considers two essential components, the probability for any breeding individual to reproduce for the first time ( $\beta$, the probability of first reproduction) and the probability of recapture $(p)$, both conditional on survival. Contrary to previous attempts at modeling recruitment, the present approach does not assume an age at which breeding propensity stabilizes to a maximum value. The flexibility achieved allows the comparison of recruitment among groups within a population and also allows one to consider the effects of environmental variables, as well as interactions between such effects. Practically, the procedure starts from a global model, based upon the a priori knowledge of the biology of the species, and assesses its fit. Then more parsimonious models are selected using Akaike's Information Criterion and likelihood ratio tests. Finally, maximum likelihood estimates of model parameters are obtained with estimates of precision. We used a modified version of program RELEASE for goodness-of-fit tests, and program SURGE for iterative model fitting and the computation of likelihood ratio tests. We illustrate the method with the study of local recruitment of Greater Flamingos (Phoenicopterus ruber roseus) in the Camargue (southern France) between 1984 and 1994. We found additive effects of age and year to affect recruitment. Breeding propensity increased with age. Recruitment was noticeably higher in the year following an increase in mortality rate due to a particularly severe winter. Longlasting effects of this increased mortality on recruitment were observed in the three following years. There was no evidence for an effect of sex or cohort (year of birth) on recruitment. However, sex, as well as time and age, affected recapture rates. We discuss the various advantages and limitations of the model for the study of local recruitment in long-lived species and mention some potential developments.
\end{abstract}

Key words: age-specific breeding probability; breeding propensity; capture-mark-recapture models; first reproduction; probability of; Greater Flamingo; local recruitment; Phoenicopterus ruber roseus; population dynamics; reproduction; seniority probability.

\section{INTRODUCTION}

Recruitment, the establishment of new individuals in the breeding component of populations, is a complex process, and is important both in population regulation (Birkhead and Furness 1985, Porter and Coulson 1987) and in life history theory (Lessells 1991, Roff 1992, Stearns 1992). Although natural selection is often thought to favor reproduction early in life (Charlesworth 1994), many species defer reproduction to a greater or lesser extent. For instance, long-lived birds often start to breed $\geq 1$ yr after they have completed

Manuscript received 8 November 1995; revised 29 July 1996; accepted 5 August 1996; final version received 27 September 1996.

${ }^{4}$ Address reprint requests to this author. their physiological maturation and growth (Dunnet 1991). Most explanations of delayed age at first reproduction assume a conflict between early reproduction and increase in reproductive competence with age (Brown 1987, Lessells 1991, Charlesworth 1994). Some authors have focused for instance on the importance of slow improvement of foraging skills with age (Lack 1968, Orians 1969, Ashmole 1971), whereas others considered social competition on breeding grounds, assuming a limited availability of breeding space (Coulson 1968). Previous studies demonstrated a decrease in age at first breeding following natural or anthropogenic reductions of colony densities (Duncan 1978, Potts et al. 1980, Coulson et al. 1982, Porter and Coulson 1987), in accordance with the social compe- 
tition hypothesis (Coulson 1968). Another condition that may lead to deferred reproduction is a trade-off between current reproductive effort and subsequent reproduction, growth, or survival (Charlesworth 1994). Survival of younger birds might be more sensitive to increased reproductive effort (Lack 1954) and such a fitness cost of early reproduction could delay age at first breeding. For instance, several studies of longlived species found interspecific differences in age at first breeding that they related to differences in postbreeding survival and reproductive effort (Mills 1973, Wooler and Coulson 1977). Studies of lifetime reproductive success (Clutton-Brock 1988, Newton 1989) provide evidence that various hypotheses can accommodate the large interspecific variation in age at first breeding. Variability in recruitment at the intraspecific level requires, on the other hand, an understanding of the underlying behavioral mechanisms (Porter 1990). However, most analyses of the recruitment process in natural populations so far have been hindered by a lack of appropriate statistical approaches (Clobert and Lebreton 1991, Dunnet 1991). A suitable method should provide ways for testing various hypotheses about recruitment, including environmental effects, and allow comparisons between groups of individuals.

In most previous studies (Austin and Austin 1956, Harrington 1974, Williams and Joanen 1974, Lloyd and Perrins 1977, Wooler and Coulson 1977, Duncan 1978, Finney and Cooke 1978, Harris 1981, Coulson et al. 1982, Nelson 1983, Serventy and Curry 1984, Rattiste and Lilleleht 1986, Weimerskirch and Jouventin 1987, Gratto 1988, Brooke 1990, Spendelow 1991, Thompson et al. 1994), recruitment has been equated with the age distribution of first-time breeders, without correction for variation in survival rate and/or probability of capture. However, a bird observed breeding for the first time might have bred previously. Clobert and Lebreton (1991) attributed this observed lack of formal analysis to the difficulty in obtaining separate estimates of the proportion of breeders and of survival and return rates, and emphasized the need for formal models. First attempts to model recruitment (Barrat et al. 1976, Chabrzyk and Coulson 1976, Lebreton 1978, Mougin et al. 1986) were based on simple ratio estimates of agespecific breeding probabilities from recaptures or resightings, and considered adult survival to be constant. More recently, two types of models have been proposed for the study of age-specific recruitment. Lebreton et al. (1990) proposed transversal models of recruitment for the analysis of data collected at one or several points over time, but without information on individual fate over time. Clobert et al. (1994; see also Clobert et al. 1990) developed longitudinal models to estimate agedependent recruitment from individual recapture histories of animals marked when young, considering that the probability of capture of an individual differs before and after the first recapture as a breeder. Both models depend on some critical assumptions whose biological relevance may be limited, namely that survival rates are identical for breeders and non-breeders, that survival rates are not year specific and that recapture probabilities are not age specific. In addition, the statistical models of Lebreton et al. (1990) and Clobert et al. (1994) essentially focus on the influence of age on recruitment and do not allow testing for the influence of other factors that potentially affect recruitment, such as the prevailing environmental conditions during growth, or the environmental conditions during the current breeding season. Finally, as it is most often difficult to estimate the non-breeding part of the population, all recruitment models proposed so far assumed that there is an age at which every animal still alive breeds or at least an age at which breeding propensity, i.e., the probability that an animal that has already bred will breed again (Cooke et al. 1995), becomes maximum.

The new statistical approach we present here (Pradel 1996) represents a radical change in the way in which capture histories can be studied. Capture histories are read from the last observation backward through time rather than from the first observation onwards as is usually done. In this way, when an animal ceases to be observed as a breeder, it may be reproducing for the first time or may have reproduced earlier without being detected. Recruitment thus becomes the main target of the analysis. Furthermore, this approach is also more general than previous methods in that no survival assumptions are required, and the a priori hypothesis of a stabilization in the recruitment rate after a certain age does not have to be made, but can now be tested. Finally, this approach provides more flexibility by allowing different aspects of recruitment to be analyzed directly. We first describe the general procedure and then illustrate the approach through a case study of local recruitment at the natal colony in the Greater Flamingo (Phoenicopterus ruber roseus).

\section{A Capture-Mark-Recapture Model for Testing Biological Hypotheses about Local RECRUITMENT}

\section{Link between breeding history and capture history}

The sampling scheme considered hereafter is that of a capture-mark-recapture (CMR) study carried out at a single breeding site, where individuals are marked as young and recaptured (or resighted) as breeding adults. The data are summarized in capture histories where the first observation corresponds to the year of birth and subsequent observations correspond to years when the animal is known to have bred. Thus, the model deals exclusively with local recruitment and in its present form does not address the problem of natal dispersal of birds born in the Camargue. Three periods can be distinguished in a capture history (Fig. 1): from birth to the first observed breeding attempt, the probability of joining the reproductive component of the popula- 


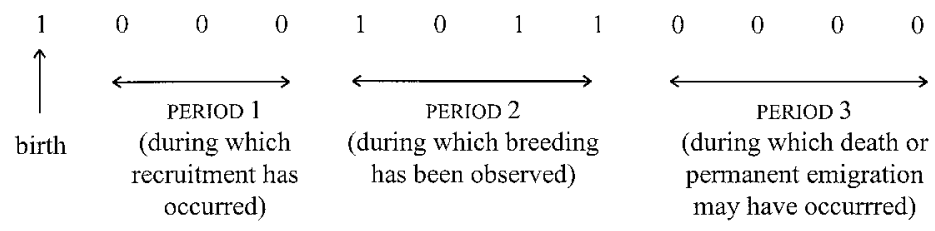

FIG. 1. Link between life history and capture/sighting history. Numbers above horizontal arrows represent capture events. tion typically increases with age; from the first to the last observed breeding attempt when the animal is alive and breeds (during which period breeding propensity may increase with age); finally, death (or permanent emigration) may occur at some point after the last observed breeding attempt. Information about recruitment is thus found in the first period and information about breeding propensity in the second period.

To extract the information about recruitment (Fig. 2), Clobert et al. (1994) use "a special case of a survival and recapture model for several data sets" that contrasts the capture rates during the first period (which rates should be relatively low because not all animals have started to breed) to those during the other periods. Their model "links the probabilities of capture with age-specific breeding probabilities" (see Clobert et al. 1994 for details). Because this model is essentially a survival model, it involves assumptions about survival, and because age-specific breeding probabilities are not directly accessible, factors affecting recruitment can only be interpreted indirectly. The approach by Pradel (1996), however, was specifically designed for the study of recruitment, although not exclusively in relation to reproduction. The method relies on two parameters (Fig. 2), the seniority probability and the recapture rate. When the model is applied to breeding animals, the seniority probability, denoted $\gamma$, corresponds to the probability that an animal breeding on a given occasion has already bred at least once. Within the framework of the study of breeding recruitment, we will consider instead the complementary event, the probability that the animal is breeding for the first time, and its associated probability (hereafter called proba- bility of first reproduction), denoted $\beta(\beta=1-\gamma)$. Details regarding the computation of $\beta$ are presented in the Appendix. The probability of first reproduction reflects recruitment whereas the capture rate, apart from capture effort, reflects breeding propensity. Both parameters can be tested against potential covariates by means of built-in constraints. Moreover, because only the first two periods of capture histories (when an animal is by definition alive) are modeled, no assumption on survival is needed.

As stated in the introduction, the core idea behind Pradel's model is to look at the capture histories backwards, from right to left (Fig. 2). Going along a capture history in this way, one may ask when an animal ceases to be a breeder and becomes an immature. Here is an example of how this idea may be formalized using seniority probability $(\gamma)$ and capture rate $(p)$. The capture history 1010100 where the first 1 represents birth (occasion 0), will be read: the animal was last caught at occasion 4, it was not recruited at 4 , was not captured at 3, was not recruited at 3, was captured at 2, and was not seen earlier than 2. The last phrase can be further expanded as: the animal was recruited at occasion 2 or was not recruited at 2, was not captured at 1 and was recruited at 1 . The associated probability is therefore $\gamma_{4}\left(1-p_{3}\right) \gamma_{3} p_{2}\left[\left(1-\gamma_{2}\right)+\gamma_{2}(1-p 1)\left(1-\gamma_{1}\right)\right]$. The same logic of computing probabilities is used in survival analysis of CMR data (Fig. 3). Indeed, recruitment models with this approach are to a large extent formally equivalent to survival models (for proof and limitations see Pradel 1996). This equivalence is important as it allows the use of pre-existing software

A) CLOBERT ET AL.'S MODEL

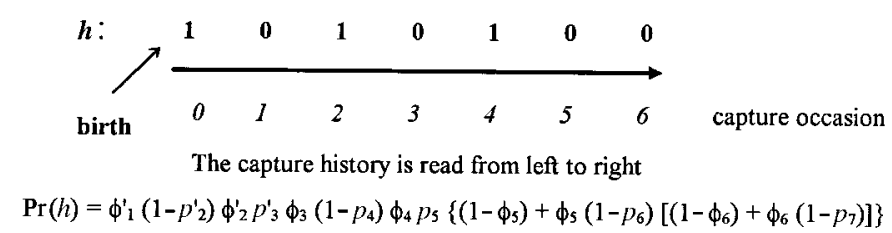

B) PRADEL'S MODEL

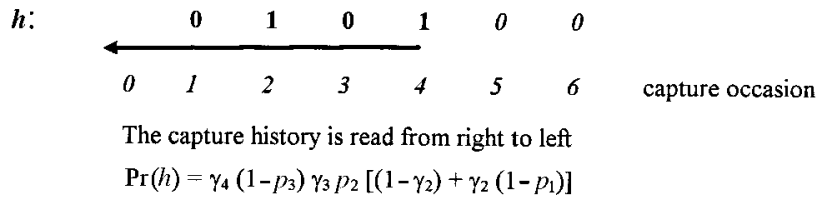

FIG. 2. Alternative parameterizations for the study of recruitment from capture histories (row of 0's and 1's labeled $h$ ). In the Clobert et al. (1994) model for the study of recruitment, $p^{\prime}=$ capture rate before recruitment, $p=$ capture rate after recruitment, $\phi^{\prime}=$ survival probability before recruitment, $\phi=$ survival probability after recruitment; $p$ and $p^{\prime}$ are further related to the age-specific breeding probabilities. In Pradel's (1996) model, $p=$ capture rate, and $\gamma=$ seniority probability, i.e., the probability that an individual has bred at least once before. Subscripts refer to occasion (for capture probability) or starting occasion (for survival probabilities). 
A)



B)

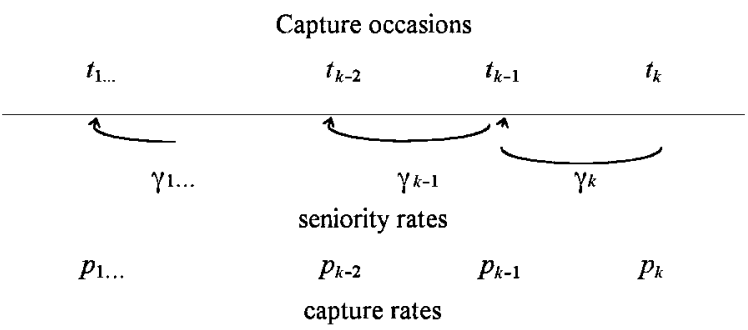

FIG. 3. Formal equivalence of survival (A) and recruitment (B) models. (A) $p_{1}$ is not estimable; (B) $p_{k}$ is not estimable. When data are read backward, first reproduction is equivalent to death; seniority probability is equivalent to survival probability.

designed for survival analysis, such as program SURGE (Pradel and Lebreton 1991) used hereafter.

\section{Preparation of the data}

To take advantage of the correspondence just mentioned between survival and recruitment analyses, data must be prepared in a specific way (Fig. 4). First, the observation corresponding to year of birth is removed from all capture histories and this information is kept separately (since age is an important factor in recruitment). Second, capture histories are reversed. Third, each cohort is made a different group. Then first reproduction becomes equivalent to mortality and estimates of seniority probability are obtained in the guise of survival probability. However, it must be noted that, because the capture histories have been reversed, the estimates of seniority probabilities will be obtained in reverse order, starting from the oldest animals. Apart from this, the recruitment analysis proceeds exactly as a survival analysis, with the identification of a general starting model that fits the data and proceeding to simpler models by eliminating the nonsignificant effects and interactions between effects. We refer the reader to the monograph of Lebreton et al. (1992) for the generalities about CMR methodology and restrict our discussion to the points specific to the study of recruitment.

\section{Goodness-of-fit test}

Goodness-of-fit tests assess whether a model correctly describes the data. In CMR, robust and well-

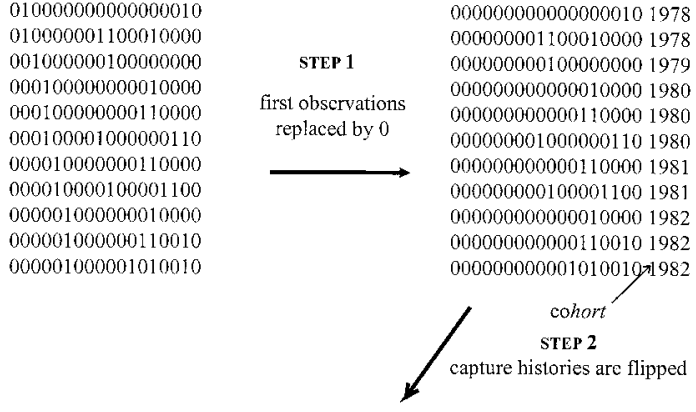

0100000000000000001978 0000100011000000001978 0000000010000000001979 0000100000000000001980 0000110000000000001980 0110000010000000001980 0000110000000000001981 0011000010000000001981 0000100000000000001982 0100110000000000001982 0100101000000000001982

STEP 3

Each cohort is a different group



FIG. 4. Preparation of the capture-mark-recapture data for an analysis of recruitment.

studied goodness-of-fit tests are available only for a few models. One such model is the Interval-Specific Survival and Capture model known as the CormackJolly-Seber model (Cormack 1964, Jolly 1965, Seber 1965). In this model, changes in survival or capture probabilities over intervals are generally thought of as temporal variations. However, when a single cohort is considered, changes among individuals may also result from the aging process. Since we know that the probability of first reproduction should strongly depend upon age, we will test the fit of the Interval-specific First Reproduction and Capture (IFRC) model on each cohort separately using the data prepared according to Fig. 4.

\section{Separating age, time, and cohort effects}

When considering only one cohort, there is no possibility of separating the respective effects of age and time on probabilities of first reproduction and capture rates. For instance, we cannot know whether, apart from expected variation with age, there are more or less favorable years for recruitment. This important question 


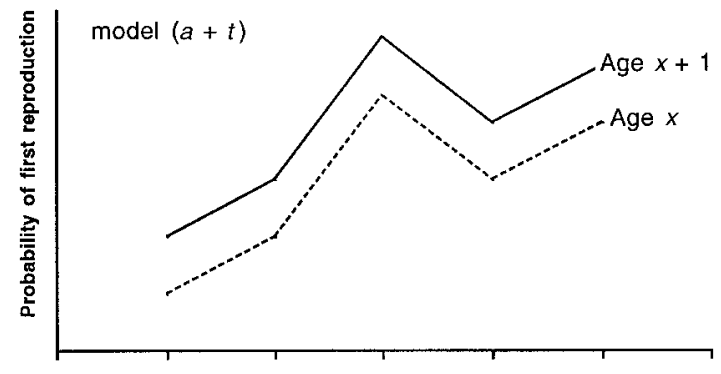

B



FIG. 5. Separating age, time, and cohort effects in the analysis of recruitment by means of additive models. We consider the recruitment of two consecutive age classes (age $x$ $=$ dotted line; age $x+1=$ continuous line) over five consecutive years. (A) model $[a+t]$ (without cohort effect), a strict parallelism over time is observed; (B) model $[a+t+$ $c$ ] (with cohort effect), individuals of age $x$ in year 1 belong to a cohort with early recruitment, the same cohort effect can again be observed for individuals of age $x+1$ in year 2 . Arrows denote the cohort effect.

necessitates that probabilities of first reproduction for a given age class are compared among several years. This can be done by comparing estimates from different cohorts in the framework of a multigroup analysis. The power to detect a time effect increases with the increasing number of marked cohorts.

Another factor that may influence recruitment is the conditions prevailing during early growth and development (see Cézilly et al. 1995). Such a factor would appear as a cohort effect in the analysis. Yet, in the presence of age and time variations, there is a priori no way to test for a cohort effect. As animals of a given age in a given year belong to a definite cohort, there is indeed no simple solution. However, the detection of a cohort effect is possible if age and time dependencies can be made more specific using some constraints. A trend with age (logit linear or a logit quadratic for instance) is a reasonable approach for recruitment. Also, variations of recruitment over time in the different age classes may be tested for parallelism (Fig. 5A). This amounts to fitting a model without interaction between age and time. Then, a cohort that recruits earlier than average will cause anomalies in the parallelism that move over time through the suc- cessive age classes (Fig. 5B). This is illustrated in the case study that follows.

\section{A Case Study: Recruitment in the Greater Flamingo \\ Methods}

Species and study area.-The Greater Flamingo is a long-lived colonial waterbird that shows delayed maturity (Johnson et al. 1993, Cézilly et al. 1996). Adult plumage is acquired only after several stages of juvenile and immature plumages (Johnson et al. 1993). There is a slight sexual dimorphism, with females being smaller in size and acquiring definitive plumage on average shortly before males (Johnson et al. 1993). Access to reproduction is progressive in flamingos; no breeding attempt by a bird $<3$ yr old has ever been observed, and breeding by birds 3 yr old is rare (Johnson et al. 1993). Details of the reproductive biology and demography of the species have been given in previous studies (Johnson 1983, Johnson 1989, Cézilly 1993, Cézilly et al. 1994a, b, 1995, 1996, 1997).

Flamingos have bred intermittently in the saline lagoons of the Camargue (southern France) for centuries (Gallet 1949, Johnson 1983). In every year from 1974 to 1994 , they have successfully bred on an artificial island built for them in the Etang du Fangassier, part of the large complex of commercial salt pans of Salin de Giraud. Depending on year and colony size, birds also have nested on a nearby dike. Since 1977, 7-30\% of young flamingos (of unknown sex) reared each year in the Camargue have been marked individually with plastic rings engraved with a three or four digit code, which allows individual recognition in the field (Johnson 1989). Originally, the larger chicks were selected for ringing, but since 1984 chicks of all sizes have been marked (Green et al. 1989).

Resightings of marked birds. - Ring codes can be read through a telescope from a distance of $\leq 400 \mathrm{~m}$. In 1982, when many of the first cohort of ringed birds were in adult plumage, observations started at the natal colony to see if any individuals were attempting to breed. The following year, a tower blind was built 70 $\mathrm{m}$ from the nesting colony in the Camargue and has been used by observers permanently during the entire breeding season each year since 1983. The observers' main activity was to determine which ringed birds were breeding. A bird was considered breeding when it was observed incubating an egg or attending a young, or when it was repeatedly observed on the same nest. Birds that were seen only courting or paired were not considered. In addition, breeding adults were also identified when feeding their chick in the crèche (see Cézilly et al. 1994b). Between 1983 and 1994, the colony ranged in size from 8600 to 19900 pairs. Table 1 shows for each study year the observation effort and the number of different ringed individuals observed.

Data analysis. - The present analysis has been re- 
TABLE 1. Number of chicks ringed for each cohort in the study, observation effort, and number of different flamingos observed at the Fangassier colony for each year during the study period.

\begin{tabular}{cccc}
\hline \hline Year & $\begin{array}{c}\text { Number of } \\
\text { chicks ringed }\end{array}$ & $\begin{array}{c}\text { Observation } \\
\text { effort }(\mathrm{h})\end{array}$ & $\begin{array}{c}\text { Number of } \\
\text { different } \\
\text { ringed birds } \\
\text { resighted }\end{array}$ \\
\hline 1977 & 559 & & \\
1978 & 650 & & \\
1979 & 651 & & \\
1980 & 761 & & \\
1981 & 697 & & \\
1982 & 652 & & \\
1983 & 720 & 756 & 194 \\
1984 & 781 & 1311 & 430 \\
1985 & 552 & 1186 & 316 \\
1986 & 599 & 1329 & 276 \\
1987 & 600 & 1138 & 277 \\
1988 & 600 & 1172 & 532 \\
1989 & & 1029 & 972 \\
1990 & & 1514 & 641 \\
1991 & & 1117 & 518 \\
1992 & & 517 & 747 \\
1993 & & 789 & \\
1994 & & & \\
\hline
\end{tabular}

stricted to the cohorts of flamingos ringed from 1977 to 1988 and resighted as breeders between 1983 and 1994 (Table 2). During the study period 824 females and 856 males of known age have been observed breeding at least once. Our analysis concerns the recapture histories of those 1680 individuals. We studied the possible influence on probabilities of first reproduction and capture probabilities of cohort, time, sex, and age through a set of models involving all or some of the main effects and of their interactions. A cohort effect may result from long-term effects of rearing conditions. A time effect is notably expected since a severe cold spell occurred in the winter 1984-1985, causing the death of an estimated 6000 flamingos, $\approx 25 \%$ of the local breeding population (Johnson et al. 1991, Lebreton et al. 1992, Cézilly et al. 1996), and presumably reducing the competition for access to the breeding island the following year.

Model notation, from Pradel (1996), is adapted from the notation of survival models (Lebreton et al. 1992), which is derived from generalized linear models notation (McCullagh and Nelder 1989). An index formula designates the effects considered for each kind of parameter, probability of first reproduction $(\beta)$ and recapture probability $(p)$, where an age effect is denoted $a$, a time (i.e., year) effect is denoted $t$, an effect of the year of birth (= cohort) is denoted $b$, a sex effect is denoted $s$. Effects are connected by asterisks (*) if they interact, and by plus signs $(+)$ if they are additive.

We started the procedure with a goodness-of-fit test of the Interval-Specific Survival and Capture (ISSC) model (see Goodness-of-fit test, above) applied separately to each combination of sex and cohort groups $\left(\beta_{s^{*} b^{*} t}, p_{s^{*} b^{*} t}\right)$. This general model can be seen as well as $\left(\beta_{s^{*} a^{*} t}, p_{s^{*} a^{*}}\right)$, where probabilities of first reproduction and recapture probabilities may take on a different value for each combination of sex, age, and time cate-

TABLE 2. Numbers of flamingos observed breeding for the first time at their native colony per year, cohort, and sex.

\begin{tabular}{|c|c|c|c|c|c|c|c|c|c|c|c|c|c|c|}
\hline \multirow[b]{2}{*}{ Cohort } & \multicolumn{14}{|c|}{ Observation year } \\
\hline & 1982 & 1983 & 1984 & 1985 & 1986 & 1987 & 1988 & 1989 & 1990 & 1991 & 1992 & 1993 & 1994 & Total \\
\hline \multicolumn{15}{|l|}{ Males } \\
\hline 1977 & 2 & 9 & 6 & 17 & 13 & 6 & 3 & 2 & 1 & 0 & 1 & 0 & 1 & 61 \\
\hline 1978 & 0 & 4 & 5 & 18 & 25 & 8 & 4 & 1 & 2 & 2 & 1 & 2 & 1 & 73 \\
\hline 1979 & 0 & 1 & 5 & 22 & 26 & 13 & 5 & 4 & 4 & 7 & 0 & 1 & 3 & 91 \\
\hline 1980 & & 0 & 1 & 12 & 39 & 15 & 6 & 5 & 6 & 8 & 3 & 0 & 1 & 96 \\
\hline 1981 & & & 0 & 8 & 33 & 12 & 6 & 12 & 11 & 11 & 0 & 3 & 6 & 102 \\
\hline 1982 & & & & 1 & 18 & 18 & 9 & 12 & 22 & 29 & 9 & 2 & 8 & 128 \\
\hline 1983 & & & & & 0 & 6 & 3 & 4 & 18 & 30 & 14 & 4 & 5 & 84 \\
\hline 1984 & & & & & & 0 & 2 & 1 & 9 & 24 & 12 & 3 & 14 & 65 \\
\hline 1985 & & & & & & & 0 & 0 & 7 & 28 & 16 & 5 & 15 & 71 \\
\hline 1986 & & & & & & & & 0 & 1 & 13 & 11 & 7 & 12 & 44 \\
\hline 1987 & & & & & & & & & 0 & 11 & 6 & 5 & 14 & 36 \\
\hline 1988 & & & & & & & & & & 0 & 2 & 0 & 3 & 5 \\
\hline \multicolumn{15}{|l|}{ Females } \\
\hline 1977 & 2 & 12 & 7 & 19 & 25 & 2 & 5 & 6 & 3 & 2 & 4 & 2 & 0 & 89 \\
\hline 1978 & 0 & 6 & 8 & 23 & 16 & 6 & 4 & 2 & 3 & 3 & 4 & 4 & 5 & 84 \\
\hline 1979 & 0 & 3 & 7 & 17 & 33 & 9 & 4 & 1 & 5 & 8 & 6 & 3 & 1 & 97 \\
\hline 1980 & & 0 & 0 & 13 & 19 & 8 & 5 & 7 & 9 & 11 & 2 & 5 & 1 & 80 \\
\hline 1981 & & & 0 & 6 & 22 & 13 & 5 & 9 & 16 & 13 & 6 & 5 & 3 & 98 \\
\hline 1982 & & & & 1 & 12 & 5 & 4 & 4 & 14 & 18 & 6 & 7 & 4 & 75 \\
\hline 1983 & & & & & 3 & 4 & 5 & 3 & 15 & 41 & 15 & 7 & 9 & 102 \\
\hline 1984 & & & & & & 0 & 0 & 1 & 13 & 38 & 8 & 3 & 8 & 71 \\
\hline 1985 & & & & & & & 0 & 0 & 9 & 25 & 8 & 6 & 9 & 57 \\
\hline 1986 & & & & & & & & 0 & 2 & 23 & 6 & 6 & 10 & 47 \\
\hline 1987 & & & & & & & & & 0 & 11 & 2 & 2 & 2 & 17 \\
\hline 1988 & & & & & & & & & & 2 & 0 & 2 & 3 & 7 \\
\hline
\end{tabular}


TABLE 3. Goodness-of-fit tests of the recruitment model by cohort applied to the reverse capture histories of Camargue flamingos. Test of model $\left(\beta_{t^{*} a_{*}^{*}}, p_{t^{*} a_{*}^{* *}}\right) ; \hat{c}$ denotes the overall overdispersion factor estimate.

\begin{tabular}{lccrrl}
\hline \hline Sex & Cohort & \multicolumn{1}{c}{$\chi^{2}$} & \multicolumn{1}{c}{ df } & $P$ \\
\hline F & 1977 & 34.0441 & 40 & 0.7345 & \\
F & 1978 & 55.5327 & 41 & 0.0644 & \\
F & 1979 & 56.0174 & 32 & 0.0054 & \\
F & 1980 & 56.3908 & 34 & 0.0093 & \\
F & 1981 & 44.7787 & 31 & 0.0522 & \\
F & 1982 & 24.0268 & 19 & 0.1951 & \\
F & 1983 & 27.2375 & 18 & 0.0746 & \\
F & 1984 & 7.4884 & 10 & 0.6787 & \\
F & 1985 & 1.1991 & 3 & 0.7532 & \\
F & 1986 & 6.8333 & 3 & 0.0774 & \\
M & 1977 & 31.8513 & 35 & 0.6209 & \\
M & 1978 & 51.196 & 37 & 0.0603 & \\
M & 1979 & 50.814 & 36 & 0.0518 & \\
M & 1980 & 46.1496 & 31 & 0.0392 & \\
M & 1981 & 36.8073 & 28 & 0.1232 & \\
M & 1982 & 39.8086 & 28 & 0.0688 & \\
M & 1983 & 20.5369 & 17 & 0.2477 & \\
M & 1984 & 34.1836 & 11 & 0.0003 & \\
M & 1985 & 15.4906 & 7 & 0.0302 & \\
M & 1986 & 3.6536 & 2 & 0.1609 & \\
M & 1987 & 0.0356 & 1 & 0.8504 & \\
Total & & 644.0759 & 464 & $<0.0001$ & $\hat{c}=1.388$ \\
\hline
\end{tabular}

gories-or as $\left(\beta_{s^{*} a^{*} b}, p_{s^{*} a^{*} b}\right)$ with similar interpretations - since an interaction between age and time corresponds to a cohort effect whereas an interaction between age and cohort corresponds to a time effect. The goodness of fit of the general model was tested using program REL-CR (Pradel 1993), a modified version of program RELEASE (Burnham et al. 1987). We then proceeded to models that were structured more simply and that were deprived of some effects or combinations of effects found in the general model. Those models were fitted using program SURGE 4.1 (Pradel and Lebreton 1991). The selection among models was based on Akaike's Information Criterion (AIC) (Akaike 1973). The use of AIC favors parsimony in model selection and thus enhances the robustness of the conclusions (Lebreton et al. 1992, Anderson et al. 1994). Goodness-of-fit tests (see next paragraph) led to the incorporation of an overdispersion factor, and the use, accordingly, of a modified AIC (noted hereafter mAIC), following Lebreton et al. (1992).

\section{RESUlts}

\section{Goodness-of-fit tests}

Table 3 shows that the IFRC model applied to the reversed capture histories was rejected $(P<0.05)$ for five cohort-sex groups out of 21 with sufficient data, as well as for the total model $\left(\beta_{t^{*} a^{*} s}, p_{t^{*} a^{*} s}\right)$. This lack of fit may a priori result from either structural deficiencies or overdispersion. Structural deficiency means that an important effect has been overlooked in the analysis. On the other hand, in the case of overdispersion, the variance is greater than expected under the assumption of a multinomial distribution due to some interdependence among individuals or heterogeneity among individuals. In order to identify the origin of the observed lack of fit we examined the value of $c$, the ratio of the overall $\chi^{2}$ value to its number of degrees of freedom. This value is on average equal to 1 when the model fits. In the present analysis, the $c$ value was reasonably small (1.388), and perfectly compatible with overdispersed count data (see Burnham et al. 1987:246-252). One way to further ascertain that extramultinomial variation is to be blamed rather than structural failure is to look at the $c$-stimates, noted $\hat{c}$, for the subcomponents of the global test. Each subcomponent should be equally affected if data are overdispersed, whereas they are likely to react differently to structural failure. Four subcomponents were available in the goodness-of-fit test as given in REL-CR, with corresponding $\hat{c}$ values $1.69,1.19,1.39$, and 1.31. These values were reasonably close to one (Burnham et al. 1987). Yet, a closer look at the contingency tables related to the highest $\hat{c}$ value (1.69) showed that animals observed for the first time tended to disappear in greater numbers than animal previously seen (test 3.SR of RELEASE). The difference was small and detectable only for some cohorts ( 8 out of 17) even with a specific test aimed at detecting systematic differences in proportions (Everitt 1977:27-29). We chose not to model this weak effect, particularly because a variance inflation factor based on the other components was needed anyway. Thus, subsequent analyses started from model $\left(\beta_{t^{*} a^{*} s}, p_{t^{*} a^{*} s}\right)$ and made use of the overall overdispersion factor estimate $\hat{c}=1.388$. Since the likelihood ratio tests (LRT) for comparison between nested models will tend to be inflated by excess variation (compared to that assumed by multinomial variation), we used instead as a test statistic the LRT/df statistic divided by $\hat{c}$, treated as an $F$ test (see Lebreton et al. 1992).

\section{Cohort-based study}

Because the most adequate sex and time structure may differ among cohorts, we chose in a first stage to study each cohort separately. If similar conclusions were reached through the separate analyses, one could confidently consider them more broadly valid. In each case, we fitted all models below the IFRC model by sex (Table 4). In this cohort-based approach, age and time are confounded because in a given year all animals are the same age. The notation " $t$ " was thus merely used for convenience. The MAIC pointed, for eight out of 12 cohorts, to time effects on probabilities of first reproduction and recapture probabilities, that is, to the IFRC model $\left(\beta_{t}, p_{\mathrm{t}}\right)$ applied to pooled males and females. However, for four cohorts, a model with an additional additive sex effect on recapture probabilities $\left(\beta_{t}, p_{t+s}\right)$ was favored, with males being more likely to be resighted than females. The next step was to proceed with an overall analysis involving all the cohorts in order to (1) separate the effects of time and age, and 
TABLE 4. Cohortwise selection among models of recruitment in the Camargue flamingos population. For each model and each cohort, we give its modified Akaike Information Criterion (mAIC). Boldface type denotes the mAIC value for the selected models.

\begin{tabular}{|c|c|c|c|c|c|c|c|c|c|c|c|c|}
\hline \multirow[b]{2}{*}{ Model } & \multicolumn{12}{|c|}{ Cohort } \\
\hline & 1977 & 1978 & 1979 & 1980 & 1981 & 1982 & 1983 & 1984 & 1985 & 1986 & 1987 & 1988 \\
\hline & 195.53 & 135.42 & 283.61 & 099.31 & 182.74 & 930.98 & 641.70 & 334.96 & 262.32 & 120.67 & 75.86 & 17.90 \\
\hline$\beta_{t+}$ & O & 11 & 1271 & 1085 & & 922 & & & & & & 17.90 \\
\hline $\mathrm{P}_{t+s}$ & 6.85 & 112 & 127 & & & 924 & & & & 12 & 74 & 17.90 \\
\hline & 171.90 & 1111.69 & 1257.99 & 1074.05 & 1.63 & 913.47 & 630.19 & 318.50 & 254.74 & 118.47 & 74.42 & 17.90 \\
\hline & 1184.98 & 1125.87 & 1274.91 & 1090.30 & 1179.87 & 931.20 & 637.44 & & 257.40 & 120.48 & 72.81 & 17.90 \\
\hline & & & 1261. & 1 & & 9 & & & & & 70.84 & 17.90 \\
\hline & 179.03 & 1129.99 & 1269.75 & 1085.02 & 68 & 920.63 & 635.53 & 329.30 & 256 & & 72.06 & 17.90 \\
\hline$t+8$ & 1170.14 & 1111.11 & 1256.22 & 1072.06 & & 912.31 & 628.33 & 319.16 & & & 70.62 & 17.90 \\
\hline & 1166.36 & 1109.76 & 1258.00 & 1079.15 & 1161.87 & 920.24 & 624.61 & 316.08 & 251.93 & 112.89 & 66.84 & 14.83 \\
\hline
\end{tabular}

Notes: Model notation is adapted from Lebreton et al. (1992) with $\beta$ representing seniority probability (=1 - probability of first reproduction), $p$ recapture rate, $t$ time effect, $s$ sex effect, + additive model, and $*$ model with interaction.

(2) enhance the power of the test of a sex effect on recapture.

\section{Separating age and time effects}

Our first model, for which the goodness-of-fit test had been computed, was $\left(\beta_{t^{* * a *}}, p_{t * a * s}\right)$. Its relative deviance (given by SURGE) and MAIC were 10570.37 and 8281.02 , respectively. As the model $\left(\beta_{t}, p_{t+s}\right)$, though for some cohorts overparameterized, was the simplest model that fitted all cohort data sets, we considered as the next step this model applied separately to each cohort, i.e., the overall model $\left(\beta_{t * b}, p_{(t+s) * b}\right)$. This model represented a dramatic progress, with the dispersion factor MAIC $=8077.82$. However, age and time were still confounded. We next considered the nested model with all main effects but without interaction terms, i.e., $\left(\beta_{a+t+b}, p_{a+t+b+s}\right)$. The MAIC = 7923.47, again a dramatic decrease, indicating the absence of significant interactions. From this model on it became possible to test the different effects separately.

\section{Selecting the best combination of effects}

Starting from the additive model $\left(\beta_{a+t+b}, p_{a+t+b+s}\right)$, model selection led to model $\left(\beta_{a+t}, p_{a+t+s}\right)$ (Table 5). In this model probabilities of first reproduction are affected by age and time but not by sex, and recapture rates are affected by age, sex, and time, with all effects additive and highly significant. Cohort did not affect probabilities of first reproduction, whereas its effect on recapture rates could not be definitely ascertained. Cohort and age effects on recapture rates were so confounded that they could be substituted at any stage without much change in the quality of fit. The choice in favor of an age effect was made on the following grounds: (1) Cézilly et al. (1996) previously identified an age effect on recapture in an analysis of survival of the same flamingo population; and (2) the pattern of increase of recapture rates with age (Fig. 6) could be easily explained as resulting from an increase in breeding propensity with age (Cézilly et al. 1996) whereas the biological meaning of a similar pattern for a cohort effect was unclear (there was no reason to assume a steady improvement in the local breeding conditions through time).

\section{Quantitative effects of age}

The effect of age is better regarded as quantitative on both recapture rate and probability of first reproduction, because the breeding propensity of experienced breeders may increase with age and because the proportion of experienced birds increases from zero at age $3 \mathrm{yr}$ to a value close to one for older animals. We investigated those questions by trying linear $(A)$ and quadratic $\left(A^{2}\right)$ effects of age both on probabilities of first reproduction and recapture rates on a logit scale (Table 6). Quadratic effects of age on probabilities of first reproduction and recapture rates were clearly retained $\left(\beta_{A+t}, p_{A^{2}+t+s}\right)$, whereas linear effects were rejected. Cubic effects of age were unnecessary.

\section{Age of stabilization for probability of first reproduction}

The process of recruitment (i.e., entry into the breeding segment of the population) is supposed to end at some age, although some new individuals may continue to join the local population due to immigration. We tested different models where probability of first reproduction remained constant, all other things being equal, from a certain age onwards. The data allowed us to try all ages of stabilization from 4 to $17 \mathrm{yr}$. This latter value being the largest one in our sample, it corresponds to the previously selected model $\left(\beta_{A^{2}+t}\right.$, $\left.p_{A^{2}+t+s}\right)$. The quality of the fit did not differ among models with an age of stabilization $>9 \mathrm{yr}$ (Fig. 7). The difference between these models in MAIC was $\leq 1.5$ and models that differ by $<2$ from the lowest MAIC currently are considered equally valid (Anderson et al. 1994). We thus concluded that stabilization did not occur before $10 \mathrm{yr}$ and adopted the model with stabilization at year 10 , model $\left(\beta_{A^{2}(10)+t}, p_{A^{2}+t+s}\right)$, as the best model for the present data. Variations over age and 
TABLE 5. Elimination of nonsignificant effects from the model $\left(\beta_{a+++c}, p_{a+t+c+s}\right)$ : for each model we give the number of estimable parameters (np), the relative deviance (rDEV), and the Akaike information criterion corrected for overdispersion (mAIC). Boldface type denotes the mAIC value for the selected model.

\begin{tabular}{|c|c|c|c|c|}
\hline Model & $\mathrm{np}$ & $\mathrm{rDEV}$ & mAIC & $\begin{array}{l}\text { Null hypothesis tested } \\
\text { (current model is compared to } \\
\text { previously accepted model) }\end{array}$ \\
\hline$\left(\beta_{a+t+c}, p_{a+t+c+s}\right)$ & 69 & 10806.97 & 7923.47 & \\
\hline$\left(\beta_{a+t+c}, p_{a+t+s}\right)$ & 60 & 10823.86 & 7917.64 & $\begin{array}{l}\text { no cohort effect on recapture rate } \\
F_{9,464}=12.17, P=0.204 \\
\text { accepted }\end{array}$ \\
\hline$\left(\beta_{a+t}, p_{a+t+s}\right)$ & 51 & 10833.24 & 7906.40 & $\begin{array}{l}\text { no cohort effect on probability of } \\
\text { first reproduction } \\
F_{9,464}=9.38, P=0.403 \\
\text { accepted }\end{array}$ \\
\hline$\left(\beta_{a+t}, p_{a+t}\right)$ & 50 & 10878.56 & 7937.05 & $\begin{array}{l}\text { no sex effect on recapture rate } \\
F_{1,464}=32.65, P<0.001 \\
\text { rejected }\end{array}$ \\
\hline$\left(\beta_{a+t}, p_{a+s}\right)$ & 40 & 11194.35 & 8144.54 & $\begin{array}{l}\text { no time effect on recapture rate } \\
F_{11,464}=260.15, P<0.001 \\
\text { rejected }\end{array}$ \\
\hline$\left(\beta_{a+t}, p_{t+s}\right)$ & 38 & 10974.25 & 7981.98 & $\begin{array}{l}\text { no age effect on recapture rate } \\
F_{13,464}=101.59, P<0.001 \\
\text { rejected }\end{array}$ \\
\hline$\left(\beta_{a}, p_{a+t+s}\right)$ & 40 & 10884.32 & 7921.19 & $\begin{array}{l}\text { no time effect on probability of } \\
\text { first reproduction } \\
F_{11,464}=36.80, P<0.001 \\
\text { rejected }\end{array}$ \\
\hline$\left(\beta_{t}, p_{a+t+s}\right)$ & 38 & 10871.68 & 7908.09 & $\begin{array}{l}\text { no age effect on probability of } \\
\text { first reproduction } \\
F_{13,464}=27.69, P=0.010 \\
\text { rejected }\end{array}$ \\
\hline
\end{tabular}

Note: Model notation adapted from Lebreton et al. (1992).

year as predicted by this model are given respectively on Figs. 8 and 9. At this stage, the parsimony achieved enhances the power of the tests. Since in a backward selection procedure there is a danger of dropping an actual effect during the first steps of model selection



FIG. 6. Effect of bird age on resighting rate in a population of flamingos in the Camargue in southern France. Agespecific resighting rates are expressed relative to the value at age $16 \mathrm{yr}$ (on a logit scale). Underlying model is $\left(\beta_{a+t}\right.$, $\left.p_{a+t+s}\right)$. This model makes no assumption about the form of the relationship.
(Pradel et al. 1990), we then checked that no effect or interaction should be reintroduced among those dropped earlier. We also checked for several covariates, such as water levels around the breeding site and colony size (see Cézilly et al. 1995), and population size at different geographical scales (A. R. Johnson, unpublished data), that might explain the variations observed over time. None of those attempts succeeded.

\section{DISCUSSION}

\section{Age effect on local recruitment}

In this study of local recruitment, some birds, whatever their age, may have bred in some other colony before being observed breeding for the first time in the Camargue. Therefore, the observed age effect on the probability of first reproduction at the Camargue colony represents both the increased probability of first reproduction with age and the increase in probability of return to the natal colony to breed through time. The two effects cannot be evaluated separately in a study of local recruitment. However, a quadratic effect of age could be modelled, with marked stabilization after age $10 \mathrm{yr}$, suggesting that the individuals $>9 \mathrm{yr}$ old when observed breeding for the first time at their colony of birth were most likely to have been recruited initially in another colony from which they later dispersed (see 
TABLE 6. Treatment of age in a quantitative way in models of recruitment to a flamingo population. From model $\left(\beta_{a+t}, p_{a+t+s}\right)$ to model $\left(\beta_{A^{2}+t}, p_{A^{2}+t+s}\right)$. Same notation as in Tables 4 and 5 .

\begin{tabular}{|c|c|c|c|c|}
\hline Model & np & rDEV & mAIC & $\begin{array}{l}\text { Null hypothesis tested } \\
\text { (current model is compared to } \\
\text { previously accepted model) }\end{array}$ \\
\hline$\left(\beta_{a+t}, p_{a+t+s}\right)$ & 51 & 10833.24 & 7906.40 & \\
\hline$\left(\beta_{a+t}, p_{A^{2}+t+s}\right)$ & 40 & 10838.21 & 7887.98 & $\begin{array}{l}\text { quadratic age effect on recapture } \\
\text { rate } \\
F_{11,464}=3.58, P=0.981 \\
\text { accepted }\end{array}$ \\
\hline$\left(\beta_{a+t}, p_{A}+_{t+s}\right)$ & 39 & 10846.57 & 7892.00 & $\begin{array}{l}\text { linear age effect on recapture rate } \\
F_{1,464}=6.02, P=0.014 \\
\text { rejected }\end{array}$ \\
\hline$\left(\beta_{A^{2}+t}, p_{A^{2}+t+s}\right)$ & 29 & 10862.46 & 7883.45 & $\begin{array}{l}\text { quadratic age effect on probability of } \\
\quad \text { first reproduction } \\
F_{11,464}=17.47, P=0.095 \\
\text { accepted }\end{array}$ \\
\hline$\left.\beta_{A}+{ }_{t}, p_{A^{2}+t+s}\right)$ & 28 & 10912.49 & 7917.49 & $\begin{array}{l}\text { linear age effect on probability of } \\
\text { first reproduction } \\
F_{1,464}=36.04, P<0.001 \\
\text { rejected }\end{array}$ \\
\hline
\end{tabular}

Green et al. 1989, Nager et al. 1996). Although there is evidence that flamingos can be sexually mature at age $3 \mathrm{yr}$ (Johnson et al. 1993), it appears that for some individuals recruitment can be delayed over several more years. Various adaptive explanations for delayed recruitment have been proposed. This may correspond to variation in the breeding strategies of individuals of different quality or vigor experiencing different potential costs of reproduction (Forslund and Pärt 1995). Further information on the variation in breeding success with age and experience is needed to assess the relevance of this hypothesis for flamingos.

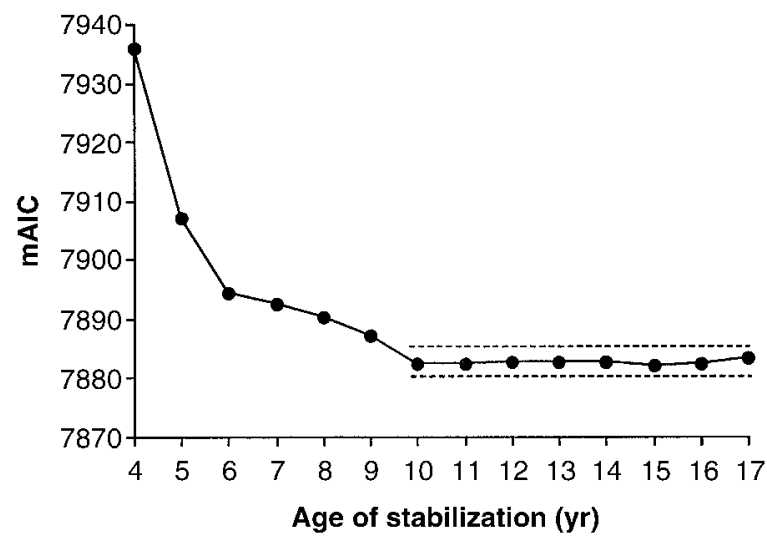

FIG. 7. The values of mAIC (a modified version of Akaike's Information Criterion) for different ages of stabilization of probability of first reproduction in a flamingo population in the Camargue of southern France. Models used are derived from model $\left(\beta_{A^{2}+t}, p_{A^{2}+t+s}\right)$ where probability of first reproduction is a quadratic logistic function of age. In the derived models, there is an age beyond which probability of first reproduction remains constant, all other things being equal The mAIC values of models with age of stabilization $>10 \mathrm{yr}$ (points between dotted lines) differ by $<1.5$.
Delayed recruitment also has been related to the need to improve foraging skills through experience (Orians 1969, Recher and Recher 1969) prior to engaging in breeding. Flamingos are filter feeders (Jenkin 1957, Zweers et al. 1995), and experimental studies have recently revealed that complex mechanisms underlie filter performances and discrimination capacity (Zweers et al. 1995). However, the variation in the efficiency of filter feeding with age in flamingos remains unexplored. Apart from limited foraging skills, competition between age classes on foraging grounds (Bildstein et al. 1991, Schmitz and Baldassarre 1992) may also reduce foraging efficiency of young individuals and, hence, delay breeding.

Finally, delayed reproduction may be the conse-

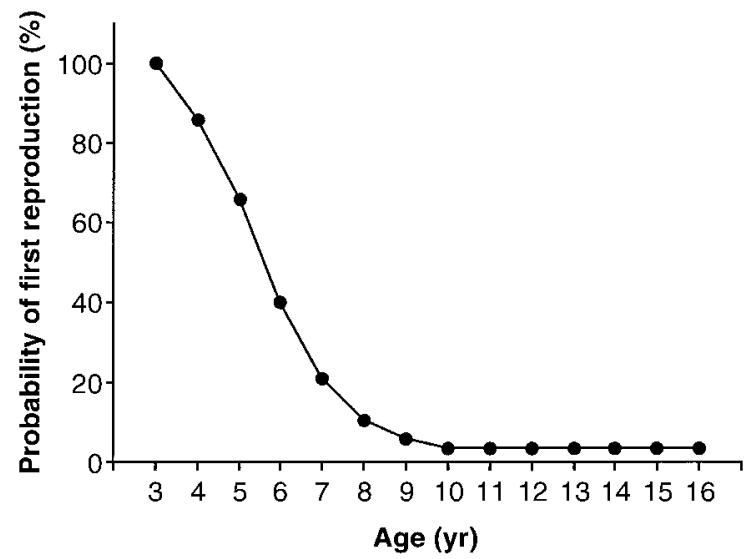

FIG. 8. Recruitment in year 1992 for the different age classes in a population of flamingos in the Camargue of southern France. Proportion of new recruits is estimated from model $\left(\beta_{A^{2}(10)+t}, p_{A^{2}+t+s}\right)$ where it remains stable from age $10 \mathrm{yr}$ onwards. 


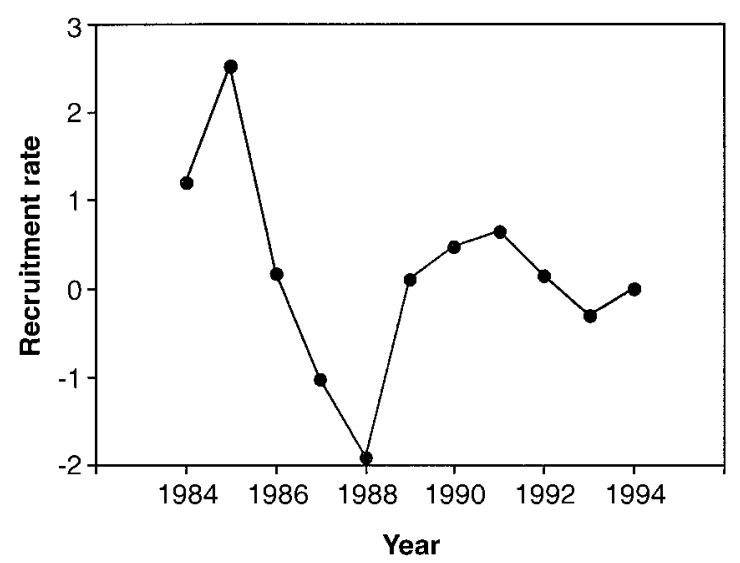

FIG. 9. Recruitment over the study period to a population of flamingos in the Camargue of southern France. The proportions of new recruits are expressed relative to values in year 1994 (on a logit scale). They are estimated from model $\left(\beta_{A^{2}(10)+t}, p_{A^{2}+t+s}\right)$.

quence of social constraints. Greater flamingos are extremely cautious in their choice of a breeding site and only a limited number of places are used in the Western Palearctic (Johnson 1983, Cézilly et al. 1994a), most of them on an irregular basis. The Camargue colony is the only regular breeding place, with several thousands of breeding pairs filling the breeding island. Each year, hundreds or thousands of individuals attend the colony site without being able to secure a nesting site on the breeding island. Reduced mating opportunities due to directional mating preference for older individuals (Cézilly et al., in press) also may force younger individuals to postpone reproduction.

\section{Time effect on local recruitment}

Time effect represents variations among years in the recruitment rate at the Camargue colony (Fig. 8), with a peak in recruitment in 1985 , followed by a marked decline over the next $3 \mathrm{yr}$. This pattern can be interpreted in relation to the wintering strategies of flamingos and to the high mortality that occurred during the winter of 1984-1985 (Cézilly et al. 1996). Previous analyses (F. Cézilly et al., unpublished data) have shown that a majority of birds that breed at the Fangassier colony have spent the previous winter in southern France. Therefore, the death of several thousands of flamingos in the south of France during the winter of 1984-1985 (Cézilly et al. 1996) dramatically reduced competition for access to breeding sites the following breeding season. Such favorable local conditions may have prompted in 1985 the recruitment of younger age classes and/or still inexperienced older individuals. Indeed, following a severe winter, the colony size at the Fangassier reached an estimated 13500 nesting pairs compared to only 10535 in 1984 (Cézilly et al. 1995). The way in which high adult mortality was, at least partially, compensated for confirms the existence of a pool of potential recruits that is ordinarily prevented from breeding (Cézilly and Johnson 1995). This pool may contain individuals not only from the Camargue but also from other colonies (Nager et al. 1996). The control of recruitment to the Fangassier colony from the pool of potential breeders appears to be then, at least partially, density-dependent. Such a mechanism of regulation has been previously suggested for Kittiwakes (Rissa tridactyla, Porter and Coulson 1987). In addition to this, the cold spell of 1984-1985 particularly affected the survival of first- and secondyear birds (Johnson et al. 1991, Lebreton et al. 1992), corresponding to cohorts 1983 and 1984, thus inducing a deficit of recruits of birds aged 4 to $6 \mathrm{yr}$ in 1987 and 1988 (Fig. 9). Also, the pool of potential recruits from the older cohorts was depleted in 1987 and 1988 as a result of the exceptional recruitment opportunities of 1985. The situation becomes normal again from 1989 onwards with the recruitment of individuals born after the cold spell. We tested this scenario in model $\left(\beta_{A^{2}(10)+t[85-88]}, p_{A^{2}+t+s}\right)$, in which there is no effect of time on probabilities of first reproduction outside the 19851988 period. Compared to model $\left(\beta_{A^{2}(10)+t}, p_{A^{2}+t+s}\right)$, model $\left(\beta_{A^{2}(10)+t[85-88]}, p_{A^{2}+t+s}\right)$, with relative deviance equal to 10867.64 , was acceptable $\left(F_{7,464}=0.576, P>0.05\right)$. Attempts to eliminate the time effect in 1985 and 1988 were rejected $\left(F_{1,464}=12.31, P=0.0005\right.$, and $F_{1,464}$ $=4.21, P=0.0402$, respectively). Thus, recruitment could be considered constant during the study period, except for the period 1985-1988. The present study shows that severe climatic conditions, such as the cold spell of 1984-1985 can deeply affect population dynamics, not only instantaneously in terms of reduced survival (Cézilly et al. 1996), but also over consecutive years in terms of recruitment.

\section{Absence of a sex effect on local recruitment}

A noticeable result of this study is the absence of sex effect on local recruitment, contrasting with previous reports for long-lived species (Mills 1973, Wooler and Coulson 1977). This result was not unexpected since there is no difference between sexes in survival (Cézilly et al.1996) and because our model corrected for the probability of recapture. Rattiste and Lilleleht (1986) showed that differences in nest-site tenacity between males and females can lead to the erroneous conclusion that one sex starts breeding earlier than the other. In a review of recruitment in long-lived birds, Bradley and Wooler (1991) also noted that the sample sizes of known-age first breeders in most studies are often small, with a large overlap in the ages at which males and females start to breed. Bradley and Wooler (1991) doubted the significance of differences between the sexes in the age of first breeding, rarely exceeding 1 yr. Despite a noticeable sexual size dimorphism in flamingos, the present study gives no support to the idea that sexual differences in the age at which breeding starts may be size related (Warham 1990). 


\section{Factors affecting recapture rates}

Additive effects of age, sex, and time were found to affect recapture rates, confirming earlier findings for the same population (Cézilly et al. 1996). Time effect is assumed to correspond to variation in observation effort among years, whereas sex effect has been related to differences between males and females in their probability of re-nesting after breeding failure (Cézilly and Johnson 1995, Cézilly et al. 1997). The age effect on capture indicates that, having reached first reproduction, a bird does not necessarily become a regular breeder from then on (Cézilly et al. 1996). Indeed, young birds, even if they have been able to find a nest site and reproduce in a previous breeding season, may not be able to secure each year a place on the nesting colony and therefore remain irregular breeders. Concerning the age effect on capture rate, the essential difference with the results of Cézilly et al. (1996) comes from the quadratic effect found on capture rate. With fewer years and hence fewer age classes represented, only a linear effect of age had been found in the previous analysis of survival (Cézilly et al. 1996).

\section{CONCLUSIONS}

\section{Advantages of the model}

Compared to previous attempts, our approach, through relaxing several unwarranted assumptions about demographic processes (such as constant survival rate across time and cohorts, or full reproduction at a given age) allows for a straightforward study of recruitment. Based on an analogy with CMR (capturemark-recapture) survival modeling (cf. Lebreton et al. 1992), an important step has been to consider separately the probability of first reproduction (the parameter of recruitment) and the probability of recapture. The advantage of such a distinction is obvious in the case study. First, in a study of recruitment based upon the age distribution of first-time breeders, the observed sex effect on the probability of recapture would have been incorrectly interpreted as a sex effect on recruitment. Secondly, in the same kind of model, as well as in more sophisticated models that still do not allow recapture probabilities to be age dependent (e.g., Clobert et al. 1994), it would not have been possible to model the stabilization of the recruitment after age 10 $\mathrm{yr}$, since the recapture probabilities of flamingos increase with age (cf. Fig. 6; see also Cézilly et al. 1996).

The study of capture histories in reverse (Pradel 1996) provides additional advantages. For instance, Clobert et al. (1994) assumed equal survival for both breeders and nonbreeders. This assumption may, however, be false, especially if there is a trade-off between survival and reproduction (Reznick 1985, Forslund and Pärt 1995) or if breeders are on average animals of higher quality with higher survival than nonbreeders. Contrasting with previous studies, the present analysis is devoid of assumptions about survival (cf. Pradel
1996). In essence, the philosophy of the approach differs basically from other attempts to model recruitment. Compared to Clobert's model, the aim of the present study is not so much to compute specific parameters, such as age-specific breeding probabilities, but rather to test explicit biological assumptions about which factors affect the process of recruitment.

\section{Age and certain breeding parameters}

The ability to test assumptions about which environmental factors affect recruitment certainly represents important progress for the study of population dynamics. Still, it may be of interest, from an evolutionary point of view, to dispose of a key parameter to compare relationships between recruitment and other life history traits (here, the age of stabilization of probability of first reproduction vs. mean age at first breeding and age-specific breeding probabilities) among populations or species (Stearns and Koella 1986, Sutherland et al. 1986, Charnov and Berrigan 1990, Harvey and Pagel 1991). For instance, the mean value for age at first breeding has previously been used to study the association between recruitment and survival among bird species using data from the literature (Lack 1968, Croxall 1981, Bradley and Wooler 1991). Indeed, most studies have considered the distribution of age-specific breeding probabilities (Lebreton et al. 1990, Clobert et al. 1994) or the mean (Porter and Coulson 1987) or median (Klomp and Furness 1991) age at first breeding as the key parameter for studying recruitment. However, in doing so, most studies have been forced to arbitrarily assume an age of maximum breeding propensity, although there is no simple way to verify it in the wild (Lebreton et al. 1990). In the present study, the key parameter for recruitment corresponds to the probability of first reproduction (Pradel 1996), with no assumption on an actual age of full reproduction. It is then possible to test for a stabilization of the probabilities of first reproduction after a certain age. Our results show that such a phenomenon does occur in the Greater Flamingo at age $10 \mathrm{yr}$. We therefore suggest that the level of stabilization of probabilities of first reproduction may be a particularly reliable parameter to characterize recruitment, and, hence, to perform comparative studies of relationships between life-history traits.

\section{Future developments}

Capture-recapture methodology is relatively inexpensive and is applicable to various populations and taxonomic groups. We have proposed a shift in emphasis from estimating age-specific breeding propensity to testing biological hypotheses about local recruitment. In this context refined questions can be addressed without resorting to ad hoc calculations that may provide misleading results. Although the model in its present form is strictly limited to the study of local recruitment, it provides a framework that should 
in the future benefit from numerous developments. First, new methods of marking should appear, or become less costly, enabling an increase in both sample sizes and the diversity of biological organisms under survey. Increased sample size will, in turn, increase the power of tests to detect significant effects affecting recruitment. Applying the method to a wide range of species will be particularly valuable for a comparative study of recruitment based on standardized estimates. Secondly, the next generation of software designed for the analysis of CMR data should explicitly address the estimation of recruitment rates. A third point is related to the development of more sophisticated models with broadened biological relevance. One of the most promising directions will be to address the trade-off between dispersal and recruitment in spatially specific CMR models. Such multi-site models would constitute powerful tools for the study of spatially organized populations, then allowing the consideration of both local recruitment and recruitment due to immigration from other colony sites.

\section{ACKNOWLEDGMENTS}

We are most grateful to the Tour du Valat Flamingo team and in particular to Philippe Pilard, Christophe Tourenq, and Dianne Wilker for assistance in data collection. We thank the Compagnie des Salins du Midi et des Salines de l'Est for allowing access to their property and the Fondation Tour du Valat for financial support. Jean-Dominique Lebreton, Jeffrey A. Spendelow, and Gary C. White provided helpful comments on earlier versions of the manuscript. R. G. Nager was supported by Schweizerische Nationalfonds, Roche Research Foundation, and Bundesamt für Bildung und Wissenschaft (grant to S. Stearns).

\section{Literature Cited}

Akaike, H. 1973. Information theory and an extension of the maximum likelihood principle. Pages $267-281$ in B. N. Petran and F. Csáki, editors. International symposium on information theory. Second edition. Akadémiai Kiadi, Budapest, Hungary.

Anderson, D. R., K. P. Burnham, and C. G. White. 1994. AIC model selection in overdispersed capture-recapture data. Ecology 75:1780-1793.

Ashmole, N. P. 1971. Seabird ecology and the marine environment. Pages 224-286 in D. S. Farner and J. R. King, editors. Avian Biology. Volume 1. Academic Press, London, United Kingdom.

Austin, O. L., and O. L. Austin Jr. 1956. Some demographic aspects of the Cape Cod population of Common Terns (Sterna hirundo). Bird-Banding 27:55-66.

Barrat, R., H. Barré, and J. L. Mougin. 1976. Données écologiques sur les grands Albatros Diomedea exulans de l'île de la Possession (archipel Crozet). L'Oiseau et la Revue Française d'Ornithologie 46:143-155.

Bildstein, K. L., P. C. Frederick, and M. G. Spalding. 1991. Feeding patterns and aggressive behavior in juvenile and adult American Flamingos (Phoenicopterus ruber). Condor 93:916-925.

Birkhead, T. R., and R. W. Furness. 1985. Regulation of seabird populations. Pages 145-167 in R. M. Sibly and R. H. Smith, editors. Behavioural ecology, ecological consequences of adaptive behaviour. Blackwell, Oxford, United Kingdom.

Bradley, J. S., and R. D. Wooler. 1991. Philopatry and age of first-breeding in long-lived birds. Proceedings of the International Ornithological Congress XX:1657-1665.

Brooke, M. de L. 1990. The Manx Shearwater. Poyser, London, United Kingdom.

Brown, J. L. 1987. Helping and communal breeding in birds. Princeton University Press, Princeton, New Jersey, USA.

Burnham, K. P., D. R. Anderson, G. C. White, C. Brownie, and K. H. Pollock. 1987. Design and analysis methods for fish survival experiments based on release-recapture. American Fisheries Society Monograph 5.

Cézilly, F. 1993. Nest desertion in the greater flamingo. Animal Behaviour 45:1038-1040.

Cézilly, F., V. Boy, R. E. Green, G. J. M. Hirons, and A. R. Johnson. 1995. Interannual variation in greater flamingo breeding success in relation to water levels. Ecology 76: $20-26$.

Cézilly, F., V. Boy, C. J. Tourenq, and A. R. Johnson. 1997. Age-assortative pairing in the Greater Flamingo, Phoenicopterus ruber roseus. Ibis, in press.

Cézilly, F., P. Gowthorpe, B. Lamarche, and A. R. Johnson. 1994a. Observations on the breeding of the Greater Flamingo, Phoenicopterus ruber roseus, in the Banc d'Arguin National Park, Mauritania. Colonial Waterbirds 17:181183.

Cézilly, F., and A. R. Johnson. 1995. Re-mating between and within breeding seasons in the Greater Flamingo, Phoenicopterus ruber roseus. Ibis 137:543-546.

Cézilly, F., C. Tourenq, and A. R. Johnson. 1994b. Variation in parental care with offspring age in the Greater Flamingo. Condor 96:809-812.

Cézilly, F., A. Viallefont, V. Boy, and A. R. Johnson. 1996. Annual variation in survival and breeding probability in the Greater Flamingo. Ecology 77:1143-1150.

Chabrzyk, G., and J. C. Coulson. 1976. Survival and recruitment in the Herring Gull Larus argentatus. Journal of Animal Ecology 45:187-203.

Charlesworth, B. 1994. Evolution in age-structured populations. Second edition. Cambridge University Press, Cambridge, United Kingdom.

Charnov, E. L., and D. Berrigan. 1990. Dimensionless numbers and life history evolution: age of maturity versus the adult lifespan. Evolutionary Ecology 4:273-275.

Clobert, J., and J.-D. Lebreton. 1991. Estimation of bird demographic parameters in bird populations. Pages 75-104 in C. M. Perrins, J.-D. Lebreton, and G. J. M. Hirons, editors. Bird population studies. Oxford University Press, Oxford, United Kingdom.

Clobert, J., J.-D. Lebreton, D. Allainé, and J. M. Gaillard. 1994. The estimation of age-specific breeding probabilities from recaptures or recaptures in vertebrate populations. II. Longitudinal models. Biometrics 50:375-385.

Clobert, J., J.-D. Lebreton, and G. Marzolin. 1990. The estimation of local immature survival rates and of age-specific proportions of breeders in bird populations. Pages 199-213 in J. Blondel, A. Gosler, J.-D. Lebreton, and R. H. McCleery, editors. Population biology of passerine birds: an integrated approach. Springer Verlag, Berlin, Germany.

Clutton-Brock, T. H. 1988. Reproductive success: Studies of individual variation in contrasting breeding systems. The University of Chicago Press, Chicago, Illinois, USA.

Cooke, F., R. F. Rockwell, and D. B. Lank. 1995. The Snow Geese of La Pérouse Bay. Natural selection in the wild. Oxford University Press, Oxford, U.K.

Cormack, R. M. 1964. Estimates of survival from the sighting of marked animals. Biometrika 51:429-438.

Coulson, J. C. 1968. Differences in the quality of birds nesting in the centre and on the edges of a colony. Nature, London 217:478-479.

Coulson, J. C., N. Duncan, and C. Thomas. 1982. Changes 
in the breeding biology of the Herring Gull (Larus argentatus) induced by a reduction in the size of the colony. Journal of Animal Ecology 51:739-756.

Croxall, J. P. 1981. Aspects of the demography of Antarctic and Subantarctic seabirds. Comité National Français des Recherches Antarctiques 51:479-488.

Duncan, N. 1978. The effects of culling Herring Gulls (Larus argentatus) on recruitment and population dynamics. Journal of Applied Ecology 15:697-713.

Dunnet, G. M. 1991. Introductory remarks: recruitment in long-lived birds. Proceedings of the International Ornithological Congress XX:1639-1640.

Everitt, B. S. 1977. The analysis of contingency tables. Chapman and Hall, London, United Kingdom.

Finney, G., and F. Cooke. 1978. Reproductive habits in the Snow Goose. The influence of female age. Condor 80:147158 .

Forslund, P., and T. Pärt. 1995. Age and reproduction in birds-hypotheses and tests. Trends in Ecology and Evolution 10:374-378.

Gallet, E. 1949. Les flamants roses de Camargue. Payot, Lausanne, Switzerland.

Gratto, C. L. 1988. Natal philopatry, site tenacity, and age of first breeding of the Semipalmated Sandpiper. Wilson Bulletin 100:660-663.

Green, R. H., G. J. M. Hirons, and A. R. Johnson. 1989. The origin of long-term cohort differences in the distribution of Greater Flamingos Phoenicopetrus ruber roseus in winter. Journal of Animal Ecology 58:543-555.

Harrington, B. A. 1974. Colony visitation behavior and breeding ages of Sooty Terns (Sterna fuscata). Bird-Banding 45:115-144.

Harris, M. P. 1981. Age determination and first breeding of Brittish puffins. British Birds 74:246-256.

Harvey, P. H., and M. D. Pagel. 1991. The comparative method in evolutionary biology. Oxford University Press, Oxford, United Kingdom.

Jenkin, P. M. 1957. The filter-feeding and food of flamingos (Phoenicopteri). Philosophical Transactions of the Royal Society of London, Series B 240:401-493.

Johnson, A. R. 1983. Ethoécologie du Flamant rose (Phoenicopterus ruber roseus Pallas) en Camargue et dans l'ouest Paléarctique. Thesis. University of Toulouse, Toulouse, France.

2. 1989. Population studies and conservation of Greater Flamingos in the Camargue. Pages 49-63 in A. L. Spaans, editor. Wetland en Watervogels. Center for Publishing and Documentation (Pudoc), Wageningen, The Netherlands.

Johnson, A. R., F. Cézilly, and V. Boy. 1993. Plumage development and maturation in the Greater Flamingo, Phoenicopterus ruber roseus. Ardea 81:25-34.

Johnson, A. R., R. E. Green, and G. J. M. Hirons. 1991 Survival rates of Greater Flamingos in the west Mediterranean region. Pages 249-271 in C. M. Perrins, J.-D. Lebreton, and G. J. M. Hirons, editors. Bird population studies. Relevance to conservation and management. Oxford University Press, Oxford, United Kingdom.

Jolly, G. M. 1965. Explicit estimates from capture-recapture data with both death and immigration-stochastic models. Biometrika 52:225-247.

Klomp, N. I., and R. W. Furness. 1991. Recruitment in longlived birds: studies of nonbreeding Great Skuas. Proceedings of the International Ornithological Congress $\mathbf{X X}$ $1678-1688$.

Lack, D. 1954. The natural regulation of animal numbers. Clarendon, Oxford, United Kingdom.

. 1968. Ecological adaptations for breeding in birds. Methuen, London, United Kingdom.

Lebreton, J.-D. 1978. Un modèle probabiliste de la dyna- mique des populations de Cigogne blanche (Ciconia ciconia L.) en Europe occidentale. Pages 277-343 in J. M Legay and R. Tomassone, editors. Biométrie et Ecologie. Société française de Biométrie, Paris, France.

Lebreton, J.-D., K. P. Burnham, J. Clobert, and D. R. Anderson. 1992. Modeling survival and testing biological hypotheses using marked animals: a unified approach with case studies. Ecological Monographs 62:67-118.

Lebreton, J.-D., G. Hemery, J. Clobert, and H. Coquillart. 1990. The estimation of age-specific breeding probabilities from recaptures or recaptures in vertebrate populations I. Tranversal models. Biometrics 46:609-622.

Lessells, C. M. 1991. The evolution of life histories. Pages 32-68 in J. R. Krebs and N. B. Davies, editors. Behavioural ecology, an evolutionary approach. Blackwell, London, United Kingdom.

Lloyd, C. S., and C. M. Perrins. 1977. Survival and age of first breeding in the Razorbill (Alca torda). Bird-Banding 48:239-252.

McCullagh, P., and J. A. Nelder. 1989. Generalized linear models. Second edition. Chapman and Hall, New York, New York, USA.

Mills, J. A. 1973. The influence of age and pair-bond on the breeding biology of the Red-billed Gull Larus novaehollandiae scopulinus. Journal of Animal Ecology 42:147163.

Mougin, J.-L., C. Jouanin, B. Despin, and F. Roux. 1986. The age of first breeding of Cory's Shearwater on Selvagem Grande and problems of ring loss. Ringing and Migration 7:130-134.

Nager, R. G., A. R. Johnson, V. Boy, M. Rendon-Martos, J. Calderon, and F. Cézilly. 1996. Temporal and spatial variation in dispersal in the Greater Flamingo (Phoenicopterus ruber roseus). Oecologia 107:204-2110.

Nelson, J. B. 1983. Contrasts in breeding strategies between some tropical and temperate marine pelecaniformes. Studies in Avian Biology 8:95-114.

Newton, I., editor. 1989. Lifetime reproduction in birds. Academic Press, London, United Kingdom.

Orians, G. H. 1969. Age and hunting success in the Brown Pelican (Pelecanus occidentalis). Animal Behaviour 17: 316-319.

Porter, J. M. 1990. Patterns of recruitment to the breeding group in the Kittiwake Rissa tridactyla. Animal Behaviour 40:350-360.

Porter, J. M., and J. C. Coulson. 1987. Long-term changes in recruitment to the breeding group, and the quality of recruits at a Kittiwake Rissa tridactyla colony. Journal of Animal Ecology 56:675-689.

Potts, G. R., J. C. Coulson, and I. R. Deans. 1980. Population dynamics and breeding success of the Shag, Phalacrocorax aristotelis, on the Farne Islands, Northumberland. Journal of Animal Ecology 49:465-484.

Pradel, R. 1993. Flexibility in survival analysis from recapture data: handling trap-dependence. Pages 29-37 in J.-D. Lebreton and P. M. North, editors. Marked individuals in the study of bird populations. Birkhäuser Verlag, Basel.

- 1996. Utilization of Capture-Mark-Recapture for the study of recruitment and population growth rate. Biometrics 52:371-377.

Pradel, R., J. Clobert, and J.-D. Lebreton. 1990. Recent developments for the analysis of capture-recapture multiple data sets. An example concerning two Blue Tit populations. The Ring 13:193-204.

Pradel, R., and J. D. Lebreton. 1991. User's manual for program SURGE, Version 4.2. CEFE/CNRS, Montpellier, France

Rattiste, K., and V. Lilleleht. 1986. Some aspects of the demography of the Common Gull Larus canus in Estonia. Vår Fågelv Supplement. 11:179-186. 
Recher, H. F., and J. A. Recher. 1969. Comparative foraging efficiency of adult and immature Little Blue Heron (Florida caerulea). Animal Behaviour 17:320-322.

Reznick, D. 1985. Costs of reproduction: an evaluation of the empirical evidence. Oikos 44:257-267.

Roff, D. 1992. The evolution of life histories. Chapman and Hall, New York, New York, USA.

Schmitz, R. A., and G. A. Baldassarre. 1992. Contest asymmetry and multiple bird conflicts during foraging among nonbreeding American Flamingos in Yuacatan, Mexico. Condor 94:254-259.

Seber, G. A. F. 1965. A note on the multiple recapture census. Biometrika 52:249-259.

Serventy, D. L., and P. J. Curry. 1984. Observations on colony size, breeding success, recruitment and inter-colony dispersal in a Tasmanian colony of Short-tailed Shearwaters Puffinus tenuirostris over a 30-year period. Emu 84:71-79.

Spendelow, J. A. 1991. Post-fledging survival and recruitment of known-origin Roseate Terns (Sterna dougallii) at Falkner Island, Connecticut. Colonial Waterbirds 14:108115.

Stearns, S. C. 1992. The evolution of life histories. Oxford University Press, Oxford, United Kingdom.

Stearns, S. C., and J. C. Koella. 1986. The evolution of phenotypic plasticity in life-history traits: predictions of reaction norms for age and size at maturity. Evolution 40: 893-913.

Sutherland, W. J., A. Grafen, and P. H. Harvey. 1986. Life history correlations and demography. Nature 320:88.

Thompson, P. S., D. Baines, J. C. Coulson, and G. Longrigg. 1994. Age at first breeding, philopatry and breeding sitefidelity in the Lapwing Vanellus vanellus. Ibis 136:474484.

Warham, J. 1990. The petrels. Their ecology and breeding systems. Academic Press, London, United Kingdom.

Weimerskirch, H., and P. Jouventin. 1987. Population dynamics of the Wandering Albatross, Diomedea exulans, of the Crozet Islands: causes and consequences of the population decline. Oikos 49:315-322.

Williams, L. E., and T. Joanen. 1974. Age of first breeding in the Brown Pelican. Wilson Bulletin 86:279-280.

Wooler, R. D., and J. C. Coulson. 1977. Factors affecting the age of first breeding of the Kittiwake Rissa tridactyla. Ibis 119:339-349.

Zweers, G., F. de Jong, H. Berkhoud, and J. C. Van den Berge. 1995. Filter feeding in flamingos. Condor 97:297-324.

\section{APPENDIX}

Link between seniority probabilities and probabilities of first reproduction

Among breeders of a given age, some individuals are naïve, i.e., they reproduce for the first time, whereas others are experienced, i.e., they have bred at least once in previous years. Thus, a breeder of a given age has a certain probability, the seniority probability, denoted $\gamma$ (Pradel 1996), of being experienced. Pradel (1996) has shown that the seniority probabilities correspond directly to the survival probabilities of the survival models when these latter models are applied to the reverse capture histories. Consequently, applying survival software to reversed capture histories allows us to compute seniority probabilities for different groups of individuals, such as males and females, and to test them for environmental effects. However, in a study of recruitment, it may be more convenient to use the complement to 1 of seniority probability, the probability that a breeder is reproducing for the first time denoted $\beta$. Fortunately, in the framework of logistic linear models, seniority probabilities and probabilities of first reproduction can be used interchangeably because logistic linear models of seniority probabilities are logistic linear models of probabilities of first reproduction. Indeed

$$
\operatorname{logit}(\gamma)=\log \left(\frac{\gamma}{1-\gamma}\right)=\log \left(\frac{1-\beta}{\beta}\right)=-\operatorname{logit}(\beta) .
$$

Thus a model that is linear in $\gamma$ on the logit scale is also linear in $\beta$ on the same logit scale.

As long as the logit is the link function (this is the default in SURGE) a model can be equivalently denoted $\left(\beta_{x}, p_{z}\right)$ or $\left(\gamma_{x}, p_{z}\right)$, where $x$ and $z$ represent any combination of effects. 